\title{
A prospective study of bowel preparation for colonoscopy with polyethylene glycol-electrolyte solution versus sodium phosphate in Lynch syndrome: a randomized trial
}

\author{
Maria W. J. van Vugt van Pinxteren • \\ Mariëtte C. A. van Kouwen • Martijn G. H. van Oijen • \\ Theo van Achterberg • Fokko M. Nagengast
}

Published online: 23 February 2012

(c) The Author(s) 2012. This article is published with open access at Springerlink.com

\begin{abstract}
Lynch gene carriers undergo regular surveillance colonoscopies. Polyethylene glycol-electrolyte solution (PEG) is routinely prescribed for bowel cleansing, but often poorly tolerated by patients. Sodium phosphate (NaP) may be an alternative. Prospective and random comparison of bowel preparation with PEG and $\mathrm{NaP}$ on colon cleansing and patients' acceptance. Patients, who previously underwent a colonoscopy, were invited to participate and randomly assigned to either PEG or NaP. They were asked to fill in a questionnaire about preparation tolerability and future preferences. The endoscopist filled out a report about the quality of colon cleansing. 125 Patients were included in the study. Nine (7\%) were excluded because of missing data. The remaining 116 patients (53 PEG and $63 \mathrm{NaP}$ ) were included in the analysis. Baseline characteristics did not differ between groups. Before colonoscopy 20 (38\%) patients using PEG experienced the preparation almost intolerable, in contrast to $7(11 \%)$ of those using $\mathrm{NaP}$ $(P=0.001)$. Eleven patients in the PEG group and 48 in
\end{abstract}

\footnotetext{
M. W. J. van Vugt van Pinxteren ( $₫)$.

M. C. A. van Kouwen - M. G. H. van Oijen - F. M. Nagengast

Department of Gastroenterology and Hepatology, Radboud

University Nijmegen Medical Centre, P.O.Box 9101,

6500 HB Nijmegen, The Netherlands

e-mail: m.vanvugt@mdl.umcn.nl

M. G. H. van Oijen

Department of Gastroenterology and Hepatology, University

Medical Centre Utrecht, P.O.Box 85500, 3508 GA Utrecht,

The Netherlands

T. van Achterberg

Scientific Institute for Quality of Healthcare, Radboud

University Nijmegen Medical Centre, Nijmegen, P.O.Box 9101,

6500 HB Nijmegen, The Netherlands
}

the $\mathrm{NaP}$ group would prefer $\mathrm{NaP}$ in the future. The colonoscopy was poorly tolerated in $17 \%$ of the individuals in both groups $(P=0.963)$. The endoscopist observed a more than $75 \%$ clean colon in $83 \%$ of patients on PEG and in $71 \%$ of patients on $\mathrm{NaP}(P=0.076)$, however the coecum $(P=$ $0.025)$ and ascending colon was cleaner after PEG. Lynch patients tolerated $\mathrm{NaP}$ better and preferred this formula for future bowel preparation. Colon cleansing was suboptimal with both treatments with a tendency towards a cleaner proximal colon with PEG.

Keywords Lynch syndrome · Colonoscopy · Polyethylene glycol · Sodium phosphate

\author{
Abbreviations \\ PEG Polyethylene glycol-electrolyte solution \\ NaP Sodium phosphate \\ MMR Mismatch repair
}

\section{Introduction}

Up to 5\% of all colorectal cancer cases are attributed to the Lynch syndrome [1].Lynch syndrome is caused by germ line mutations in one of the mismatch repair (MMR) genes MLH1, MSH2, MSH6 or PMS2 [2]. Lynch syndrome gene carriers are recommended to undergo regular endoscopic surveillance of their colon. This surveillance is preferably carried out by colonoscopy, [3, 4] in order to detect adenomas or less frequently early stages of colon cancer. It is important that the complete colonic mucosa can be inspected, especially the proximal colon, since most tumors in Lynch syndrome develop in this part of the colon. For inspection, a meticulously clean colon is therefore a prerequisite. Various colon-cleansing solutions have been 
studied in the past. Of these, a polyethylene glycol-electrolyte solution (PEG) is routinely prescribed for bowel cleansing, but it is often poorly tolerated [5-8]. Sodium phosphate $(\mathrm{NaP})$ may be an effective alternative, and is often better tolerated because of the small amount of liquid intake. However, it has other disadvantages like acute phosphate nephropathy and should be used with caution by at risk individuals and not be prescribed to patients with cardial and/or renal failure [3, 5, 7-12]. Earlier studies with PEG and NaP have shown an excellent clean colon in 18-80\% [7-12]. Patients mentioned equal acceptability about the bowel cleansing. The tolerability of bowel cleansing was about $60 \%[3,6,8-10,12-14]$. In these earlier studies it was often not clear if the study participants underwent a surveillance colonoscopy previously, nor was information about special patient groups available. The aim of this study was to randomly compare the effects of preparation on bowel cleansing with PEG or $\mathrm{NaP}$ and to evaluate the acceptance of the two solutions by Lynch syndrome gene carriers who used PEG as colon cleansing in the past.

\section{Methods}

\section{Patients}

This single blinded study was carried out at the department of Gastroenterology and Hepatology in a Dutch University hospital. During 1 year, Lynch syndrome gene carriers, who were scheduled for a surveillance colonoscopy, were asked to participate in the study. They were enrolled in a surveillance colonoscopy program and underwent at least one colonoscopy previously at which they used PEG as preparation on bowel cleansing. Patients with a history of colonic surgery were excluded. All procedures took place in the afternoon. Participants were randomly and singleblindly assigned to either PEG (Norgine bv, Amsterdam, the Netherlands) or NaP (Ferring, Hoofddorp, the Netherlands).

Lynch syndrome gene carriers are generally healthy persons without physical and medical restrictions to use $\mathrm{NaP}$.

Patients who were assigned to the PEG-group were given a special dietary prescription. 2 days before colonoscopy only lightly digestible products will be consumed and at the day before colonoscopy only fluid products. In addition, at the day before colonoscopy they had to use 15 gram magnesium sulfate and $10 \mathrm{mg}$ bisacodyl (both orally) (Boehringer Ingelheim, Alkmaar, the Netherlands). At the day of colonoscopy patients had to use 4 litres PEG or at least enough until the stool is clear. PEG was not given as a split-dose. Patients who were assigned to the NaP group used a lightly digestible breakfast and lunch at the day before colonoscopy, as prescribed in the instructions for use. After lunch at the day before colonoscopy, they consumed only clear fluids, at least 3 litres until the colonoscopy. In the evening before colonoscopy $45 \mathrm{ml}$ of $\mathrm{NaP}$ had to be taken. Three hours before colonoscopy another $45 \mathrm{ml}$ of $\mathrm{NaP}$ had to be used. Informed consent was obtained and the study was approved by the local Medical Ethical Committee.

\section{Instruments}

The quality of bowel cleansing was assessed for each segment of the colon (descending, transverse and ascending colon and the coecum) and graded as excellent (no fecal matter), good (small amounts of thin, liquid fecal matter; easy to remove), fair (moderate amounts of thick liquid fecal matter; difficult to remove) and poor (large amounts of thick liquid or solid fecal matter; not to remove) (Table 1).

During the day of preparation before colonoscopy and 1 week after colonoscopy, patients were asked to fill in a questionnaire about their experiences with the dietary pattern, potential interference with daily activities, tolerance and side effects of the bowel preparation and the taste of the liquid. They were also asked to mention their preferences for a bowel preparation in the future. The questionnaires were filled in at home before and 1 week after colonoscopy. The endoscopist (blinded for the way of bowel cleansing) filled out a report about the effectiveness of bowel cleansing and the duration of the introduction time and the time of the whole colonoscopy ranked as $12.5 \mathrm{~min}$ or less, $12.5-25 \mathrm{~min}, 25-37.5 \mathrm{~min}$ and more than $37.5 \mathrm{~min}$. The endoscopy nurse (also blinded for the way of bowel cleansing) filled out a report about the observation of signs of pain during colonoscopy. The pain score was ranked on a visual analog score from 1 to 5 as no pain (1); mild pain (2); moderate pain (3); severe pain and more sedation is necessary (4) and interrupted colonoscopy because of very severe pain (5).

Statistical analysis

Data were collected and entered into an electronic database. All calculations were carried out using the Statistical Package for the Social Sciences Program (SPSS version

Table 1 Cleansing grading score by the endoscopist

\begin{tabular}{ll}
\hline $\begin{array}{l}\text { Excellent } \\
\text { Good }\end{array}$ & $\begin{array}{l}\text { No fecal matter in the colon } \\
\text { Small amounts of thin, liquid fecal matter in the colon; } \\
\text { easy to remove }\end{array}$ \\
Fair & $\begin{array}{c}\text { Moderate amounts of thick liquid fecal matter in the } \\
\text { colon; difficult to remove }\end{array}$ \\
Poor & $\begin{array}{l}\text { Large amounts of thick liquid or solid fecal matter in the } \\
\text { colon; unable to remove }\end{array}$ \\
\hline
\end{tabular}


16.0 (SPSS, Chicago, Illinois, USA). Frequency tables were provided for description of patients and bowel cleansing characteristics and were compared between groups. Descriptive statistics were computed for all variables. These included means, medians and standard deviations. Pearson's Chi-square test was used to analyze associations between baseline characteristics, differences for PEG and $\mathrm{NaP}$, quality and side effects of bowel cleansing and results of cleansing. $P$ value below 0.05 (two-sided) was considered statistically significant.

\section{Results}

During a 1 year study period, 125 consecutive Lynch gene carriers participated in the study $(100 \%)$. Of these 125 patients, nine $(7 \%)$ were excluded because of missing data; they did not send back one or both questionnaires. The remaining 116 patients (M/F 58/58, mean age $50 \pm 30$ years) were included in the analysis. Fifty-three patients received PEG and $63 \mathrm{NaP}$. Twenty-three (20\%) participants underwent one colonoscopy in the past, 59 (51\%) underwent 2-5 colonoscopies, 31 (27\%) had 6-10 colonoscopies and $3(2 \%)$ patients underwent more than 10 colonoscopies (median 3).

In only one patient the special diet at the day before colonoscopy interfered with daily activities $(0.6 \%)$. Eighty four percent of all patients did not mention any or only little problems at the day before the colonoscopy. At the day of colonoscopy the preparation with the laxative interfered with their daily activities in nineteen patients (16\%). Twenty patients using PEG (38\%) found the preparation almost intolerable in contrast to seven $(11 \%)$ patients using $\mathrm{NaP}$ $(P=0.001)$ before colonoscopy. A week after colonoscopy $24(45 \%)$ patients using PEG and 47 (75\%) of those using $\mathrm{NaP}$ evaluated the preparation as tolerable $(P=0.001)$. Twenty-two (42\%) patients using PEG and $11(17.5 \%)$ using $\mathrm{NaP}$ mentioned the preparation as neutral $(P=0.004)$. At least seven (13\%) patients using PEG (four of them evaluated the preparation as more difficult afterwards) and five (8\%) patients using $\mathrm{NaP}$ ) (the same five patients who communicated this before) evaluated the preparation as intolerable (Fig. 1). The most commonly mentioned side effects of the preparation were nausea, abdominal cramps and flatulence; these side effects were mentioned in the instructions of PEG and NaP. Patients also commonly mentioned that they suffered from feeling cold; this was not mentioned as a possible side effect in the instructions of PEG and NaP (Table 2). Sixty percent of all patients using PEG and $58 \%$ of patients using NaP used 41 of fluids or more before colonoscopy; equal to or more than prescribed.

Twenty-one patients (18\%) had a preference for using PEG in the future (six of them randomized to $\mathrm{NaP}$ in this

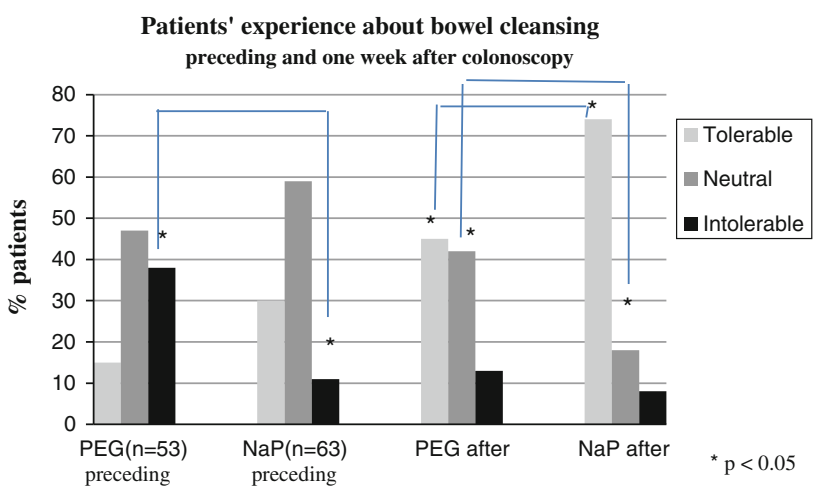

Fig. 1 Patients'experience about bowel cleansing

Table 2 Side effects of bowel preparation (measured before colonoscopy)

\begin{tabular}{lccc}
\hline & PEG-group $(n, \%)$ & NaP-group $(n, \%)$ & $P$ value \\
\hline Nausea & $24(21)$ & $20(17)$ & 0.134 \\
Vomiting & $4(3)$ & $6(5)$ & 0.706 \\
Abdominal & $23(20)$ & $27(23)$ & 0.953 \\
$\quad$ cramps & & & \\
Flatulence & $15(13)$ & $13(11)$ & 0.336 \\
Physical cooling & $34(30)$ & $34(30)$ & 0.267 \\
Insomnia & $8(7)$ & $8(7)$ & 0.709 \\
\hline
\end{tabular}

study), $59(51 \%)$ preferred to use NaP (11 of them randomized to PEG in this study) and 31 (27\%) of the patients had no preference (22 PEG/9 NaP). Five patients (4\%) did not mention their preference. In nine $(17 \%)$ of the individuals using PEG and in 11 (18\%) of the NaP participants the colonoscopy was equally poorly tolerated.

The endoscopist $(n=8)$ reported a clean colon in 44 participants (83\%) using PEG and also in 44 patients $(71 \%)$ using NaP. In 19 (36\%) of the total group of PEG users and $13(21 \%)$ of the NaP users the endoscopist observed a more than $75 \%$ complete clean colon $(P=0.076)$. In $42 \%$ of the PEG group the coecum was excellent clean, compared to $22 \%$ in the NaP group $(P=0.02)$ (Table 3$)$. In $11 \%$ the ascending colon was poorly cleaned in the $\mathrm{NaP}$ group, compared to $2 \%$ in the PEG group $(P=0.05)$. The introduction time into the coecum and the duration of the whole colonoscopy did not significant differ between both groups. In both PEG (29\%) and $\mathrm{NaP}(25 \%)$ the introduction time into the coecum was about $12.5 \mathrm{~min}(P=0.645)$ while in PEG (9\%) and NaP (13\%) the introduction time has taken more than $37.5 \mathrm{~min}$. The majority of patients $(80 \%)$ received midazolam as sedation during the colonoscopy. During the colonoscopy the endoscopy nurse observed pain on a visual analog score in 73 (33 PEG and $40 \mathrm{NaP}$ ) of all patients (47\%); of them 17 (15\%) suffered from a lot of pain (6 PEG and $11 \mathrm{NaP}$ ). In one case (NaP) the 
Table 3 Quality of bowel cleansing for segments of the colon (n, \%)

\begin{tabular}{|c|c|c|c|c|c|c|c|c|}
\hline & \multicolumn{2}{|l|}{ Coecum } & \multicolumn{2}{|c|}{ Ascending colon } & \multicolumn{2}{|c|}{ Transverse colon } & \multicolumn{2}{|c|}{ Descending colon } \\
\hline & PEG & $\mathrm{NaP}$ & PEG & $\mathrm{NaP}$ & PEG & $\mathrm{NaP}$ & PEG & $\mathrm{NaP}$ \\
\hline Excellent & $22(42)^{\#}$ & $14(22)$ & $19(36)$ & $14(22)$ & $17(32)$ & $12(19)$ & $14(26)$ & $12(19)$ \\
\hline Good & $16(30)$ & $20(32)$ & $16(30)$ & $26(41)$ & $24(45)$ & $32(51)$ & $25(47)$ & $25(40)$ \\
\hline Fair & $12(22)$ & $19(30)$ & $17(32)$ & $16(26)$ & $11(21)$ & $18(29)$ & $12(23)$ & $24(38)$ \\
\hline Poor & $3(6)$ & $10(16)$ & $1(2)^{\#}$ & $7(11)$ & $1(2)$ & 1(1) & $2(4)$ & $2(3)$ \\
\hline
\end{tabular}

\# $P=<0.05$ in favour of PEG

colonoscopy was stopped because of extreme pain. Fiftyfive patients mentioned complaints (flatulence or abdominal pain) after colonoscopy, which always disappeared within $24 \mathrm{~h}$.

\section{Discussion}

Persons at risk for colon cancer, especially Lynch syndrome gene carriers, benefit from regular surveillance colonoscopies [15]. For an optimal detection of colonic neoplasia a clean colon is very important [11]. To achieve a clean colon, compliance with the bowel preparation regimen is necessary. The most commonly used bowel cleansing solutions are often burdensome to patients because of the large amounts of fluids and their bad taste [11]. To our knowledge no information is available about the experience of bowel preparation in Lynch patients in a regular colonoscopy program. In this study all patients were able to tolerate the preparation regime, in contrast to some other studies [9, 13].

\section{Clean colon}

In patients with Lynch syndrome the increased risk for developing colon cancer is highest in the colon proximal to the splenic flexure [16]. It is therefore particularly important to examine this part meticulously and it is essential that this part of the colon is excellently cleaned. We found a comparable clean colon in the PEG and NaP group [17]. In assessing this, we used the same criteria for "poor" clean, "fair" clean, "good" clean and "excellent" clean colon as described in previous studies [5, 7, 8, 11-14, 18]. Also the same segments of the colon were evaluated [7, 9, $11,12,18]$. It was remarkable that, in contrast to other studies, we found an excellent clean colon only in $27.6 \%$ of the participants, regardless of the bowel cleansing. A significant difference in an excellent clean coecum was found in favour for PEG preparation (42\% vs. $22 \%$ ). Moreover, in the ascending colon the quality of bowel cleansing was significantly more poor in the $\mathrm{NaP}$ group $(11 \%$ vs. $2 \%)$. The cleansing efficacy of PEG in non-Lynch patients was comparable for both left and transverse colon, but the cleanliness was also superior in the coecum and ascending colon in a previous Dutch study [9].

\section{Tolerance}

Nausea was mentioned as a moderate side effect of the colon cleansing in both PEG and NaP groups; we found no difference between the groups, which was in accordance with other studies $[5,7,8,11,14]$.

In our study both PEG and NaP users often suffered from feeling cold; in other studies no information was found about this side effect. The $60 \%$ of patients, who drank 4 litre fluids or more, did not consume the drinks at the same time. Patients who used PEG, drank this amount at the day of colonoscopy and patients' who used $\mathrm{NaP}$, drank this amount in 2 days; nevertheless many of them mentioned this side effect.

Twenty-five percent of all patients poorly tolerated the cleansing preparation; however, a week after the colonoscopy only $10 \%$ of the participants mentioned that the preparation was not tolerable. Probably not only the taste and the amount of the cleansing liquid are of influence on patients' perception. It is also possible that fear for the colonoscopy itself, the fear for the outcome of the colonoscopy and the consequences of these results to the future influenced patients' perception.

Overall, in contrast to some other studies, [12, 14] because of the amount of the liquid, the acceptance of the bowel preparation was in favour for $\mathrm{NaP}$, however the taste of the liquid was similar for both groups [9].

\section{Pain}

The information of the endoscopy nurse about the observation of pain during the endoscopy was in line with the patients' information about their experience of the colonoscopy. In the PEG group, there was a tendency towards less pain.

\section{Preference}

Patients who used PEG or NaP most of time prefer to use the same formula for bowel cleansing in the future or they 
mentioned no preference. In the total group 51\% was in favour of $\mathrm{NaP}$. The same acceptability was found in other studies [11, 14]. Thirty-three percent of the users in the PEG group, who did not endure PEG in the present study, mentioned a preference for $\mathrm{NaP}$, even although they did not know anything about the liquid's taste or possible side effects of $\mathrm{NaP}$.

In our study $\mathrm{PEG}$ and $\mathrm{NaP}$ are both effective as preparation for bowel cleansing with a tendency to a cleaner colon with PEG. This is in accordance with some earlier studies, $[5,6,8$, $9,11,12,14,19,20]$ but the most important observation was a significantly more clean proximal part of the colon with PEG preparation [21]. This last finding is important with regards to the afore-mentioned high risk of neoplasia in the proximal colon in Lynch syndrome.

To our knowledge this is the first study relating to bowel cleansing in Lynch gene carriers. Although this study was conducted in a small group of gene carriers, who visited the outpatient clinic in one hospital, we conclude that bowel preparation, in this representive group of Lynch gene carriers, is not optimal with both preparations. In the proximal part of the colon PEG seems to clean the mucosa better than NaP. These findings suggest that for optimal (proximal) bowel cleansing in Lynch syndrome PEG is a better option than $\mathrm{NaP}$. The efficacy of bowel cleansing should always be more important than patient preferences in determining the choice of bowel preparation. Maybe other reasons than taste and amount of cleansing liquid are of influence at patients' acceptability for bowel cleansing. So it seems mandatory that in patients at high risk of (proximal) colon cancer, better cleaning regimes as well as patients' acceptance should be developed and investigated.

Acknowledgments The authors thank all patients who filled in the questionnaires and Mrs. Dr. Margriet Moret-Hartman for her support in statistical procedures.

Conflict of interest The authors declare that they have no conflicts of interest.

Open Access This article is distributed under the terms of the Creative Commons Attribution License which permits any use, distribution, and reproduction in any medium, provided the original author(s) and the source are credited.

\section{References}

1. Koornstra JJ, Vasen HF (2007) Surveillance colonoscopy practice in Lynch syndrome in the Netherlands: a nationwide survey. World J Gastroenterol 13(34):4658-4659

2. Botma A, Nagengast FM, Braem MG et al (2010) Body mass index increases risk of colorectal adenomas in men with Lynch syndrome: the GEOLynch cohort study. J Clin Oncol 28(28): 4346-4353

3. Parente F, Marino B, Crosta C (2009) Bowel preparation before colonoscopy in the era of mass screening for colo-rectal cancer: a practical approach. Dig Liver Dis 41(2):87-95
4. de Jong AE, Vasen HF (2006) The frequency of a positive family history for colorectal cancer: a population-based study in the Netherlands. Neth J Med 64(10):367-370

5. Aoun E, Abdul-Baki H, Azar C et al (2005) A randomized singleblind trial of split-dose PEG-electrolyte solution without dietary restriction compared with whole dose PEG-electrolyte solution with dietary restriction for colonoscopy preparation. Gastrointest Endosc 62(2):213-218

6. Barkun A, Chiba N, Enns R et al (2006) Commonly used preparations for colonoscopy: efficacy, tolerability, and safety-a Canadian Association of Gastroenterology position paper. Can J Gastroenterol 20(11):699-710

7. El Sayed AM, Kanafani ZA, Mourad FH et al (2003) A randomized single-blind trial of whole versus split-dose polyethylene glycol-electrolyte solution for colonoscopy preparation. Gastrointest Endosc 58(1):36-40

8. Huppertz-Hauss G, Bretthauer M, Sauar J et al (2005) Polyethylene glycol versus sodium phosphate in bowel cleansing for colonoscopy: a randomized trial. Endoscopy 37(6):537-541

9. Mathus-Vliegen EM, Kemble UM (2006) A prospective randomized blinded comparison of sodium phosphate and polyethylene glycol-electrolyte solution for safe bowel cleansing. Aliment Pharmacol Ther 23(4):543-552

10. Tan JJ, Tjandra JJ (2006) Which is the optimal bowel preparation for colonoscopy - a meta-analysis. Colorectal Dis 8(4):247-258

11. Hwang KL, Chen WT, Hsiao KH et al (2005) Prospective randomized comparison of oral sodium phosphate and polyethylene glycol lavage for colonoscopy preparation. World J Gastroenterol 11(47):7486-7493

12. Lee J, McCallion K, Acheson AG, Irwin ST (1999) A prospective randomised study comparing polyethylene glycol and sodium phosphate bowel cleansing solutions for colonoscopy. Ulster Med J 68(2):68-72

13. Ell C, Fischbach W, Keller R et al (2003) A randomized, blinded, prospective trial to compare the safety and efficacy of three bowel-cleansing solutions for colonoscopy (HSG-01*). Endoscopy 35(4):300-304

14. Schanz S, Kruis W, Mickisch O et al (2008) Bowel preparation for colonoscopy with sodium phosphate solution versus polyethylene glycol-based lavage: a multicenter trial. Diagn Ther Endosc 2008:713521

15. Taupin D, Chambers SL, Corbett M, Shadbolt B (2006) Colonoscopic screening for colorectal cancer improves quality of life measures: a population-based screening study. Health Qual Life Outcomes 4:82

16. Nagengast FM, Speth PA, van Tongeren JH (1984) Familial colon carcinoma. Ned Tijdschr Geneeskd 128(17):796-800

17. Lawrance IC, Willert RP, Murray K (2011) Bowel cleansing for colonoscopy: prospective randomized assessment of efficacy and of induced mucosal abnormality with three preparation agents. Endoscopy 43(5):412-418

18. Love J, Bernard EJ, Cockeram A et al (2009) A multicentre, observational study of sodium picosulfate and magnesium citrate as a precolonoscopy bowel preparation. Can J Gastroenterol 23(10):706-710

19. Juluri R, Eckert G, Imperiale TF (2011) Polyethylene glycol versus sodium phosphate for bowel preparation: a treatment arm meta-analysis of randomized controlled trials. BMC Gastroenterol 11:38

20. Kossi J, Kontula I, Laato M (2003) Sodium phosphate is superior to polyethylene glycol in bowel cleansing and shortens the time it takes to visualize colon mucosa. Scand J Gastroenterol 38(11): $1187-1190$

21. Belsey J, Crosta C, Epstein O et al (2012) Meta-analysis: the relative efficacy of oral bowel preparations for colonoscopy 1985-2010. Aliment Pharmacol Ther 35(2):222-237 